\title{
Health Indicators among Elderly People with Chronic Diseases in Beni-Suef
}

\author{
Abdelrahman Gaber Abdalla ${ }^{1,2}$, Faten Said Abd El-Hady ${ }^{2}$ \\ Sahar Sedky ${ }^{3}$, Noha Ahmed Mohammed ${ }^{4}$,
}

${ }^{1}$ Nurse Specialist, Fayoum University Hospital, Egypt

${ }^{2}$ Lecturers of Community Health Nursing Faculty of Nursing, Beni-Suef University, Beni-Suef, Egypt

${ }^{3}$ Assistant professor of pediatric of Health Nursing Faculty of Nursing, Beni-Suef University, Egypt,

${ }^{4}$ Assistant professor of community health Nursing Faculty of Nursing, Beni-Suef University, Egypt

Email: bedogaber906 @gmail.com

Tel: +201024004000

\begin{abstract}
Background. Chronic diseases and their risk factors have a substantial impact on elderly health. Chronic disease indicators are essential for surveillance, prioritization, and evaluation of elderly health interventions. Aim of the study: To assess selected health indicators among elderly with chronic diseases in Beni Suef Design: A descriptive study design was utilized in this study. Setting: The study was conducted in two outpatient clinics (medical and chest clinics) at Beni Suef University hospital. A convenient sample of one hundred elderly patients was selected in this study. Method: two tools were used,: I:Interviewing questionnaire composed of six parts part I to assess sociodemographic characteristics, part II: to assess elderly medical history for chronic diseases, part III older people quality of life questionnaire to assess quality of life, part IV: Katz index to assess the Activities of Daily Living (ADL), part V: questionnaire to assess determinants of health as ( body mass index, risk factors and lifestyle part VI : questionnaire to assess health system indicators (e.g., health care access, cost, quality and follow up. Tool II Hamilton depression scale to assess the severity of depression Result: More than three-quarters of the studied sample had a sufficient quality of life. $77 \%$ were independent in ADL, while $23 \%$ were dependent and needed help. $89 \%$ of the elderly have depression as a result of chronic diseases. Moreover, $65 \%$ of the studied sample had insufficient levels of awareness regarding healthy lifestyle and risk factors. With regard to health system indicators, $96 \%$ experienced difficulty accessing health care services. $83 \%$ of the elderly have a body mass index in the normal range. $79 \%$ were nonsmokers. Conclusion Severity of depression, determinants of health, and lifestyle indicators were significantly impacted by chronic diseases, while quality of life and ADL indicators were less affected by chronic diseases. Recommendations Replication of the study in different settings with a large study sample to generalize the results. Create an educational programme to raise nurses' awareness of chronic diseases, their indicators, and the importance of the monitoring process in improving elderly health.
\end{abstract}

Key words: Health indicators, Chronic disease, Elderly people

Receive Date : 29/11/2021

Accept Date: 8/12/2021

Publish Date : 1/1/2022 


\section{Introduction}

The term "elderly" has varied over time and in response to geographical differences in life expectancy. Anyone over the age of 65 is considered elderly in most developed nations, although the age is 60 in underdeveloped ones. In all parts of the world, life expectancy has increased significantly, more than doubling in the last century. Because of continuing advancements in health and improvements in living conditions (1).

Aging is a natural part of life. This stage of life must be experienced at one's own time and speed. Aging is a reflection of all the changes that occur over one's life. Middle age is when the elderly begin to notice age-related changes such as greying hair, wrinkled skin, and some physical decline. Even the healthiest and most attractive people are not immune to these changes. Physical impairment and functional disability occur slowly and steadily, resulting in increased dependency as people age. (2).

Sensory alterations, muscular weakening, diminished mobility, and fat changes are all part of normal ageing. As a result, chronic diseases such as hypertension, cardiovascular disease, diabetes, and a variety of neurological disorders are becoming increasingly common in the elderly. There are various functional changes in the respiratory system of the aged, including a decrease in vital capacity, an increase in residual volume, and a decrease in gas exchange. There is also a decrease in the number of functioning glomeruli and renal blood flow. There is also a drop in basal metabolism, as well as changes in the gastrointestinal and hypothalamic-pituitaryadrenal systems (3).

Chronic diseases are more common in the elderly around the world. Chronic diseases are defined by geriatric physicians as illnesses that last a year or longer and necessitate continuing medical care and/or restricted activities of daily living. The phrase "chronic diseases" is the subject of heated controversy. Heart disease, hypertension, type 2 diabetes, and obesity, for example, are all classified as chronic diseases by the Centers for Disease Control (CDC). Depression and cardiovascular illnesses, to mention a few, are among the 19 chronic conditions listed by the Centers for Medicare and Medicaid Services (4).

Chronic diseases are usually incurable, necessitate ongoing medical care, and have a significant impact on a person's everyday life. According to statistics, 80-92\% of the elderly have at least one chronic disease, and $50-77 \%$ have two or more. The most common chronic diseases in the elderly are cardiovascular disease, chronic obstructive 
pulmonary disease, and diabetes. One of the most common causes of impairment is diabetes. It's the biggest cause of kidney failure, amputations of lower limbs, and new cases of blindness in the elderly. Chronic diseases are also said to account for roughly 63 percent of all fatalities worldwide, causing significant economic harm to all countries, particularly developing countries (5).

The World Health Organization (WHO) created a global monitoring framework to measure progress in preventing and controlling major chronic diseases such as cardiovascular disease, chronic lung disease, and diabetes on a worldwide scale. Nine global targets and 25 indicators are included in the framework, which will be up for endorsement by member states during the WHO assembly in May 2013. Member states are urged to consider developing national chronic illness targets and indicators based on the global framework once it has been adopted. The nine voluntary international targets are targeted at reducing global mortality from the four chronic diseases while also speeding up action against the top risk factor (6).

Nurses, who make up the majority of health-care employees, may make a big difference when it comes to dealing with chronic diseases in the elderly. To improve client outcomes, an emphasis on preventive self-management, organizational reform, and political change is required. To achieve these adjustments, nurses will need to have specialized expertise. Nurses are increasingly needed to work with communities and other sectors to intervene early in the prevention of chronic diseases in the elderly. Nurses must use evidence-based practice (EBP) that has been shown to have favorable effects in order to do this effectively. Not just in the manner of direct client care, but also in the mode of indirect client care (7).

\section{Significance of study:}

Chronic diseases are widely acknowledged as one of the primary causes of disability, morbidity, and mortality. They have a long duration and a gradual progression. Cardiovascular disease, chronic respiratory illness, and diabetes account for $82 \%$ of all chronic disease-related deaths globally. In 2012, more than $40 \%$ of these deaths were premature (before the age of 70 ), with low and middleincome countries accounting for $82 \%$ of these deaths. We can define the behaviour of epidemiological indicators and guide the design of prevention and control 
measures if we understand the multifactorial complexity of chronic diseases in each geographical area (8).

The elderly represent a large sector of the population everywhere. Around 8.5 percent of the world's population is 65 or older. Given this situation, we propose describing the status of chronic disease indicators and key risk factors among this large group of people aged 60 and up in order to assist governments and other stakeholders in accelerating action, reducing exposure to common chronic disease risk factors, and allowing national health systems to respond effectively (9).

The number of elderly people in Egypt is 5.28 percent of the total population. There is a gradual increase in the absolute and relative numbers of elderly people. This trend is expected to continue over the next decades to be $9.2 \%$ by the end of 2021 and is expected to reach $20.8 \%$ by 2050 , so special attention should be given to elderly people, as they have a right to live and do an effective role and to be productive members of the community (10).

\section{Aim of the study:}

- The aim of this study was to assess selected health indicators among elderly people with chronic diseases at Beni-Suef through.

1) What is the impact of chronic diseases on quality of life among studied elderly people?

2) What is the level of independence in activities of daily living among studied elderly people with chronic disease?

3) What is the level of depression among studied elderly people with chronic disease?

4) What are the determinants of health affected by chronic disease among studied elderly people?

\section{Method}

\section{Research design:}

A descriptive research design was utilized to conduct the study.

Setting: The setting of the study was conducted in two outpatient clinics (medical and chest clinics) at Beni-Suef University Hospital. The hospital has 26 clinics serving around 800 to 1000 patients every day. There is no special clinic for elderly people.

Subjects: A convenience sample was included from the pre-mentioned setting. The 
total number of studied samples was 100 elderly patients who had already been diagnosed with one of the following chronic diseases: diabetes, hypertension, or chronic obstructive pulmonary disease for at least 3 months, fully oriented to place, people, and time. They also must have full insight and judgment, both sexes, of older adults with the age group of 60 years old or more.

Tools of data collection: The current study employed two tools used to collect data:

I: Structured Interviewing Questionnaire: It was developed by the investigator, under the supervision of staff, based on reviewing related literature and expert opinions and written in a simple Arabic language. It comprised six parts to assess the following:

Part1: Socio demographic characteristics of the elderly people it consists of 7 items closed ended questions (Question No 1-7) about (gender, age, residence, marital status, work, salary, and educational level).

Part 2: Elderly medical history of chronic diseases consisted of 3 items closed ended questions (Question No 8-10) about (history of the following diseases: hypertension, diabetes, and COPD).

Part 3: Older People's Quality of Life Questionnaire (OPQOL) (Moradi et al., 2020). (11)

To assess the quality of life for elderly people, which consists of 9 domains including a total of 34 items These domains cover areas such as: life overall, health and functioning, social relationships, independence, control over life, freedom, home and neighborhood, psychological and emotional wellbeing, financial circumstances, leisure and social activities, and religion and culture.

Part 4: Katz Index of Independence in Activities of Daily Living (ADL) (Bonilla et al., 2020) (12):

To assess functional status as measurement of the studied elderly people ability to perform activities of daily living independently it consists of six items (bathing, dressing, toileting, transferring, continence and feeding) 
Part 5: Determinants of health (as BMI, risk factors and life style) (Buyl et al., 2020) (13).

This tool, modified by the researchers and approved by the supervisors to assess elderly determinants of health, is composed of two parts:

A: To assess elderly lifestyle behavior and risk factors for chronic diseases. The questionnaire form consists of 15 close-ended questions emphasizing personal hygiene, meals, correctly using vegetables, fruits, protein, fat, dairy, exercise, sleep health, smoking, social activities, general examination, and consumption of food supplements.

B: Body Mass Index (BMI) is a simple calculation using a person's height and weight. The formula is

$\mathbf{B M I}=\mathrm{kg} / \mathrm{m}^{2}$

Where $\mathrm{kg}$ is a person's weight in kilograms and $\mathrm{m} 2$ is their height in meters squared.

Part 6: Health system indicators (health care access, cost, quality and use of immunization and follow up (Braithwaite et al., 2017) (14).

This part was modified by the investigator under the guidance of supervisors based on reviewing textbooks, related articles, and research studies to assess health system indicators in terms of health care access, cost, availability, and effectiveness of services. It includes four statements The first statement is to assess the accessibility of general, the second statement to assess the affordability or financial accessibility, the third statement to assess the cost of services, and the last statement to assess the effectiveness of health care services.

\section{Tool II: Hamilton depression rating scale (HAM -D) (Nixon et al., 2020) (15):}

Intended to assess the degree of depression in persons over the age of 65 who have chronic diseases. Depressed mood, guilt, suicide, sleeplessness, work and interests, retardation, agitation, anxiety, weight loss, insight, diurnal change of his symptoms, depersonalization, derealization, paranoid symptoms, and obsessional symptoms are just few of the symptoms he may experience.

Field work: The researcher conducted the study for the studied sample in the selected settings at medical and chest clinics at Beni-Suef University Hospital in 
Beni-Suef governorate over a six-month period, beginning in January 2020 and ending in June 2020.The researcher visited the selected hospital from 10 am to 12 mid-day, two days a week, to collect patients' data. The average time needed for the sheet was around 30-45 minutes. The average number interviewed individually was four elderly people per week, depending upon the understanding and response of the interviews. The elderly and nurses were informed about the study's goal, purpose, and significance.Nurses in the hospital cooperated with me in data collection.

Administrative Design: An official letter from Beni Suef University's nursing faculty was delivered to the director(s) of the intended study setting (Beni-Suef University hospital).A full explanation of the aim of the study was explored with him. Official permission to conduct the study was obtained from the responsible authorities. Oral consent was obtained from each elderly patient before conducting the interview. The title, objectives, study technique, and tools were illustrated for cooperation. If the patient is not able to read and write or is physically impaired, the researcher helped him to clarify each point accordingly.

Ethical Considerations: All ethical consideration was issued; oral consent was being obtained from each elderly patient before conducting the interview and given them a brief orientation to the purpose of the study. They were also reassured that all information gathered would be in a confidential manner and used only for the purpose of the study. No names were required on the forms to ensure anonymity and confidentiality. They were also informed about their right to withdraw at any time from the study without giving any reasons.

Statistical Analysis: The Statistical Software Package for Social Science (SPSS) version 20 was used to analyze the data. Numbers, percentages, means, and standard deviations were used to express qualitative data. Person correlation (r) was used to detect associations between quantitative variables. 


\section{Results}

Table (1): Percentage distribution of studied sample according to their sociodemographic characteristics $(n=100)$

\begin{tabular}{|c|c|}
\hline Sociodemographic characteristics & (N) $\%$ \\
\hline \multicolumn{2}{|l|}{ Gender } \\
\hline Male & 56.0 \\
\hline Female & 44.0 \\
\hline \multicolumn{2}{|l|}{ Age } \\
\hline 60 to less than 65 & 36.0 \\
\hline 65 to less than 70 & 16.0 \\
\hline 70 to less than 75 & 32.0 \\
\hline 75 to less than 80 & 16.0 \\
\hline \multicolumn{2}{|l|}{ Residence } \\
\hline Rural & 22.0 \\
\hline Urban & 78.0 \\
\hline \multicolumn{2}{|l|}{ Marital status } \\
\hline Married & 59.0 \\
\hline Single & 0.0 \\
\hline Widower & 41.0 \\
\hline \multicolumn{2}{|l|}{ Occupation } \\
\hline Retired (not working) & 70.0 \\
\hline working & 30.0 \\
\hline \multicolumn{2}{|l|}{ Income as reported by the patients } \\
\hline Enough & 42.0 \\
\hline Not enough & 17.0 \\
\hline Enough and save from it & 41.0 \\
\hline \multicolumn{2}{|l|}{ Educational level } \\
\hline Illiterate & 48.0 \\
\hline Read and write & 23.0 \\
\hline Intermediate education & 17.0 \\
\hline University education & 12.0 \\
\hline
\end{tabular}

Table 1: shows that $56 \%$ of the studied samples were males. Furthermore, $78 \%$ of the studied samples reside in urban areas, and $42 \%$ of them had enough monthly income. In addition, $48 \%$ of them were illiterate. 
Figure (1): Percentage distribution of studied sample according to their medical history $(n=100$

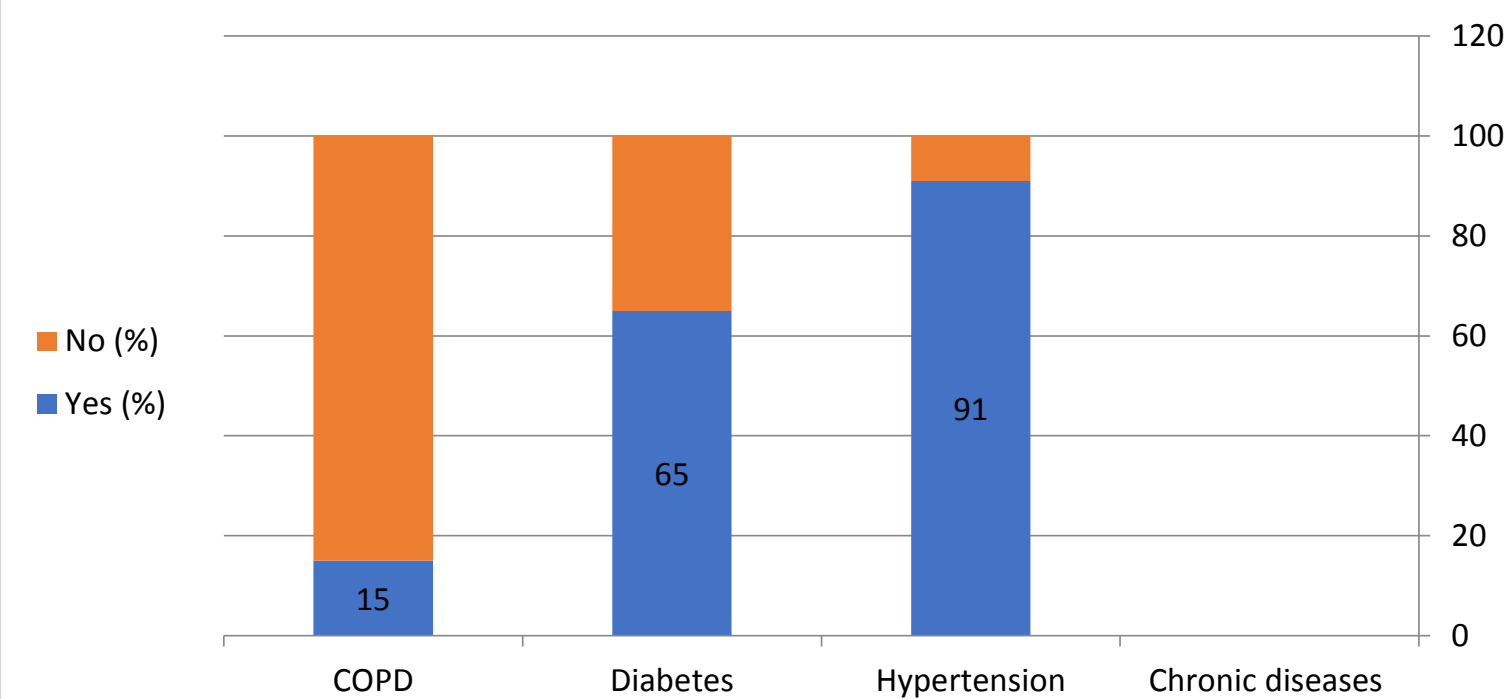

Figure (1): Reveals that $91 \%$ of the studied sample had a history of hypertension, $65 \%$ had diabetes, and $15 \%$ of them had a history of COPD.

Table (2): Percentage distribution of studied sample according to total Quality of Life $(\mathrm{n}=100)$.

\begin{tabular}{|l|c|c|c|l|}
\hline \multicolumn{1}{|c|}{ Items } & $\begin{array}{c}\text { satisfactory } \\
(\mathbf{N}) \%\end{array}$ & $\begin{array}{c}\text { unsatisfactory } \\
(\mathbf{N}) \%\end{array}$ & Mean & \multicolumn{1}{|c|}{ SD } \\
\hline 1. Life overall & 97.0 & 3.00 & 71.58 & 9.12 \\
\hline 2. Health and functioning & 83.0 & 17.0 & 66.60 & 5.24 \\
\hline 3. Social relationships & 64.0 & 36.0 & 60.79 & 17.49 \\
\hline $\begin{array}{l}\text { 4. Independence, control } \\
\text { over life, freedom }\end{array}$ & 48.0 & 52.0 & 59.04 & 11.18 \\
\hline $\begin{array}{l}\text { 5. Psychological and } \\
\text { emotional well-being }\end{array}$ & 59.0 & 41.0 & 72.00 & 20.44 \\
\hline $\begin{array}{l}\text { 6. Financial circumstances } \\
\text { 7. Leisure and social } \\
\text { activities }\end{array}$ & 54.0 & 46.0 & 66.57 & 14.82 \\
\hline 8. Religion/culture & 87.0 & 13.0 & 81.68 & 15.01 \\
\hline Total quality of life & 94.0 & 6.00 & 82.34 & 17.37 \\
\hline
\end{tabular}


Table (2) shows that $97 \%$ of the studied sample was satisfied with their lives in general, $94 \%$ believed in their culture or religion, and $87 \%$ engaged in leisure and social activities. Furthermore, $83 \%$ of the studied sample have excellent health and functioning, while 52\% are dependent and have no control over their lives/freedom. And $46 \%$ of them have financial strain.

Figure (2); Percentage distribution of studied sample according to Total Independence in Activities of Daily Living $(n=100)$.

\section{figure 1 total katz index of independence in activities of daily living No.}

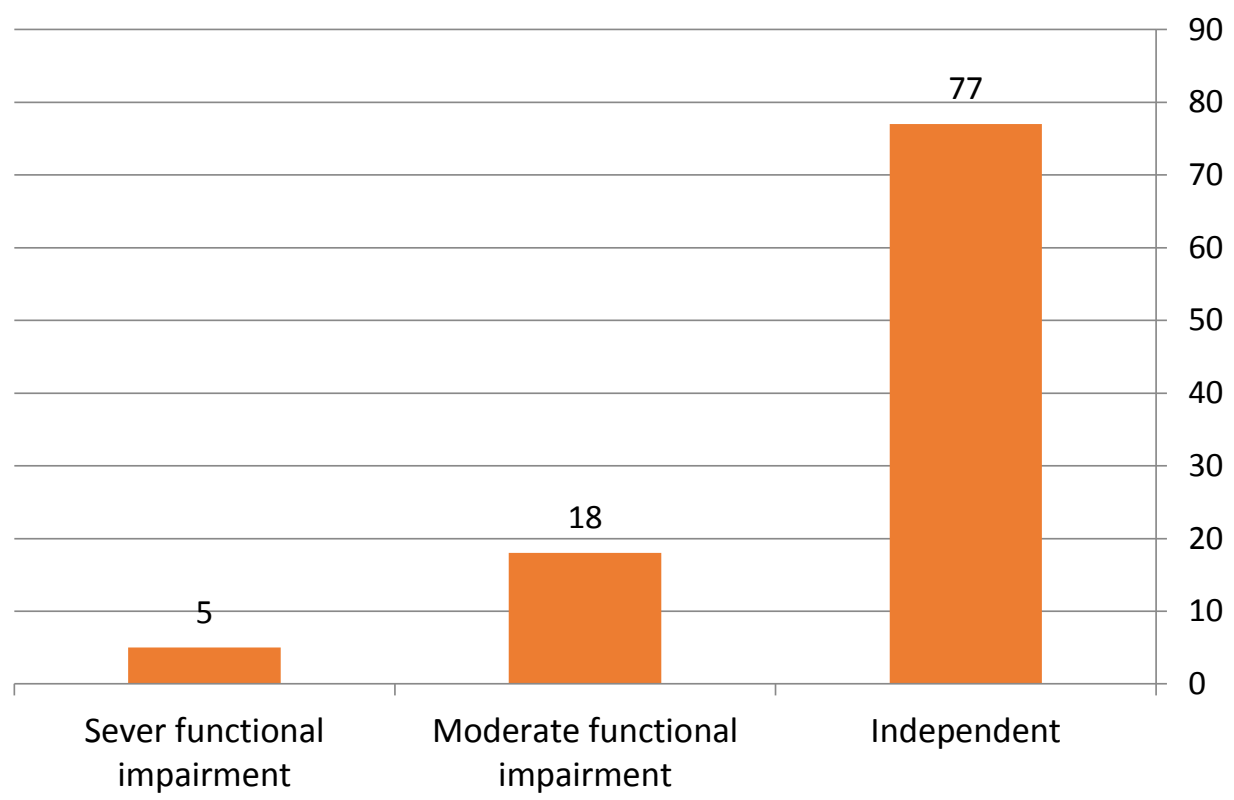

figure 1 total katz index of independence in activities of daily living No.

Figure (2): shows that $77 \%$ of the studied sample was completely independent in all daily activities, while $23 \%$ were completely dependent on all daily activities. $18 \%$ of the totally dependent have moderate functional impairment. 
Figure (3): Percentage distribution of total awareness of healthy lifestyle $(n=100)$.

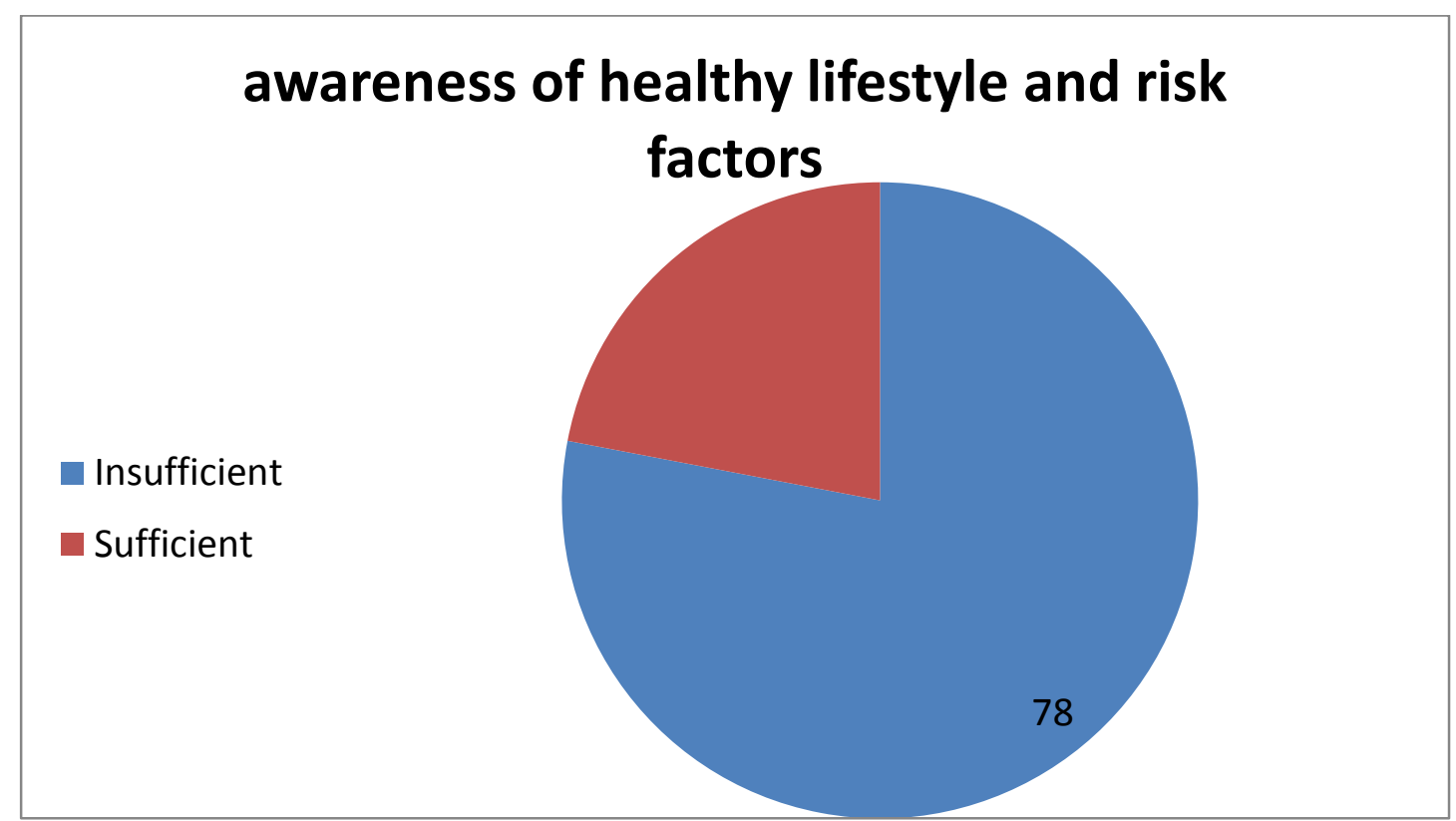

Figure (3) shows that $65 \%$ of the studied sample had insufficient awareness regarding healthy lifestyle and risk factors, while 35\% of them had sufficient awareness of healthy lifestyle and risk factors.

Figure (4): Percentage distribution of studied sample regarding their Body mass index $(n=100)$.

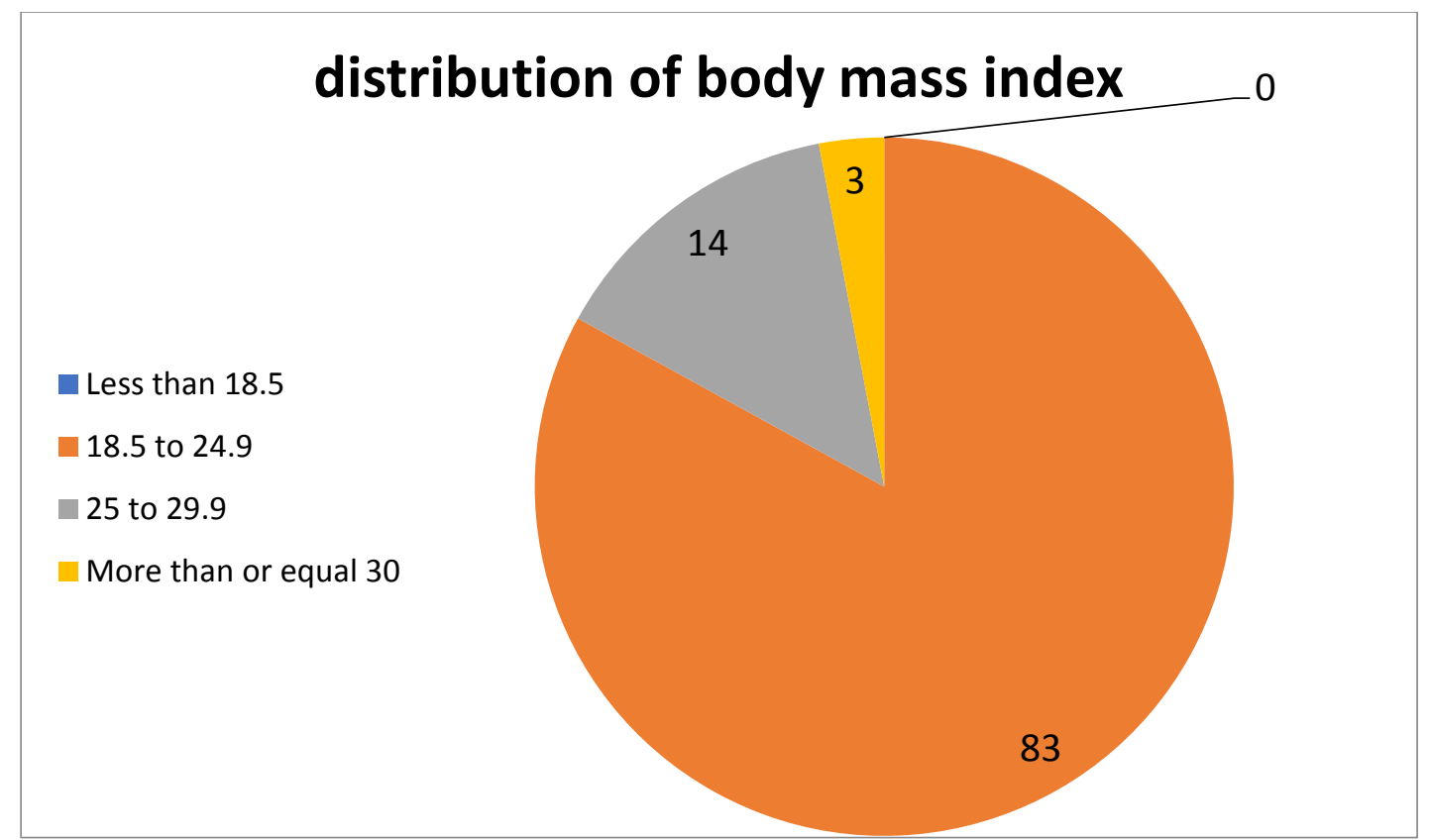

Figure (4) shows that $83 \%$ of the studied sample had a body mass index of 18.5 to 24.9 , and $14 \%$ of them had a body mass index of 25 to 29.9 . 
Table (3):Percentage distribution for health system indicators for studied sample $(\mathrm{n}=100)$

\begin{tabular}{|c|c|c|c|}
\hline Health system indicators & (N) $\%$ & mean & SD \\
\hline $\begin{array}{l}\text { Have difficulties when to obtain the healthcare } \\
\text { services needed within the past } 12 \text { months }\end{array}$ & & & \\
\hline Very difficult & 8.00 & \multirow{5}{*}{2.47} & \multirow{5}{*}{0.70} \\
\hline Difficult & 43.0 & & \\
\hline Moderate & 45.0 & & \\
\hline Easy & 4.00 & & \\
\hline Very easy & 0.00 & & \\
\hline \multicolumn{4}{|l|}{$\begin{array}{l}\text { have financial difficulties as a result of spending } \\
\text { on healthcare }\end{array}$} \\
\hline Never & 20.0 & \multirow{4}{*}{2.57} & \multirow{4}{*}{1.05} \\
\hline Rarely & 25.0 & & \\
\hline Sometimes & 33.0 & & \\
\hline Regularly & 22.0 & & \\
\hline \multicolumn{4}{|l|}{$\begin{array}{l}\text { My healthcare costs are covered to a sufficient } \\
\text { degree by my healthcare system (whether it is tax } \\
\text { based or social insurance based)? }\end{array}$} \\
\hline Strongly agree & 0.00 & \multirow{6}{*}{2.48} & \multirow{6}{*}{0.50} \\
\hline Agree & 52.0 & & \\
\hline Neutral & 48.0 & & \\
\hline Disagree & 0.00 & & \\
\hline Strongly disagree & 0.00 & & \\
\hline Don't know & 0.00 & & \\
\hline \multicolumn{4}{|l|}{$\begin{array}{l}\text { Mark all that apply. when seeking care for your } \\
\text { condition(s) }\end{array}$} \\
\hline I need to go to another city to get the service I need & 6.00 & \multirow{4}{*}{2.97} & \multirow{4}{*}{0.78} \\
\hline I need to go to another region to get the service I need & 14.0 & & \\
\hline I need to go to another town to get the service I need & 57.0 & & \\
\hline None of the above & 23.0 & & \\
\hline
\end{tabular}


Table (3) shows that $45 \%$ of the studied sample faces moderate barriers, and $43 \%$ of them face difficulty accessing health care services. $33 \%$ of the studied sample has financial barriers to receiving care. While $52 \%$ of the studied sample agree that health care costs are covered by the healthcare system, and $57 \%$ of them travel to other locations to receive appropriate care.

Figure (5); Percentage distribution of studied sample according to total severity of depression.

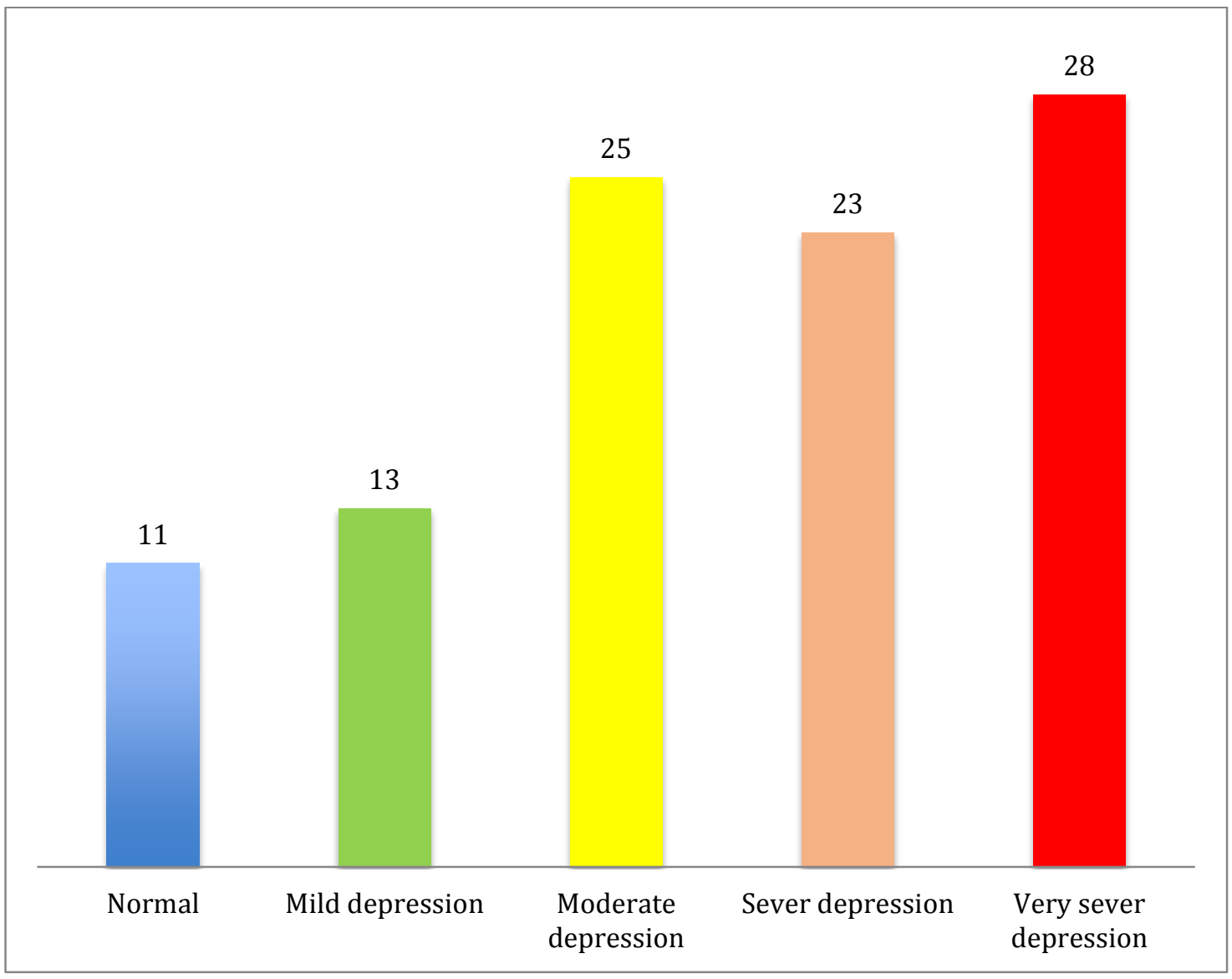

Figure (5) shows that $28 \%$ of the studied sample experienced very severe depression, $25 \%$ of them were classified as moderate depression, and $23 \%$ of them had severe depression. 
Table4: Relation between Socio-demographic characteristics awareness on healthy lifestyle among studied subjects.

\begin{tabular}{|c|c|c|c|c|c|c|c|}
\hline & \multirow{3}{*}{ No } & \multicolumn{4}{|c|}{$\begin{array}{c}\text { Awareness on Healthy Lifestyle } \\
\text { during Aging }\end{array}$} & \multirow{3}{*}{$X^{2}$} & \multirow{3}{*}{$P$ value } \\
\hline & & \multicolumn{2}{|c|}{ healthy } & \multicolumn{2}{|c|}{ unhealthy } & & \\
\hline & & No. & $\%$ & No. & $\%$ & & \\
\hline $\begin{array}{l}\text { Gender } \\
\text { Male } \\
\text { Female }\end{array}$ & $\begin{array}{l}56 \\
44\end{array}$ & $\begin{array}{l}34 \\
31\end{array}$ & $\begin{array}{l}52.3 \\
47.7\end{array}$ & $\begin{array}{l}22 \\
13\end{array}$ & $\begin{array}{l}62.9 \\
37.1\end{array}$ & 1.028 & 0.311 \\
\hline $\begin{array}{l}\text { Age } \\
\text { From } 60 \text { to less than } 65 \\
\text { From } 65 \text { to less than } 70 \\
\text { From } 70 \text { to less than } 75 \\
\text { From } 75 \text { to less than } 80\end{array}$ & $\begin{array}{l}36 \\
16 \\
32 \\
16 \\
\end{array}$ & $\begin{array}{c}19 \\
6 \\
24 \\
16\end{array}$ & $\begin{array}{c}29.2 \\
9.2 \\
36.9 \\
24.6\end{array}$ & $\begin{array}{c}17 \\
10 \\
8 \\
0\end{array}$ & $\begin{array}{c}48.6 \\
28.6 \\
22.9 \\
0.0 \\
\end{array}$ & 17.705 & $0.000 * *$ \\
\hline $\begin{array}{l}\text { Place of residence } \\
\text { Rural } \\
\text { Urban }\end{array}$ & $\begin{array}{l}22 \\
78\end{array}$ & $\begin{array}{c}3 \\
62 \\
\end{array}$ & $\begin{array}{c}4.6 \\
95.4\end{array}$ & $\begin{array}{l}19 \\
16\end{array}$ & $\begin{array}{l}54.3 \\
45.7\end{array}$ & 32.708 & $0.000 * *$ \\
\hline $\begin{array}{l}\text { Marital status } \\
\text { Married } \\
\text { Single } \\
\text { Widower } \\
\end{array}$ & $\begin{array}{c}59 \\
0 \\
41 \\
\end{array}$ & $\begin{array}{c}35 \\
0 \\
30 \\
\end{array}$ & $\begin{array}{c}53.8 \\
0.0 \\
46.2 \\
\end{array}$ & $\begin{array}{c}24 \\
0 \\
11 \\
\end{array}$ & $\begin{array}{c}68.6 \\
0.0 \\
31.4 \\
\end{array}$ & 2.039 & 0.153 \\
\hline $\begin{array}{l}\text { Occupation } \\
\text { Retired } \\
\text { Handicraft } \\
\text { Office work }\end{array}$ & $\begin{array}{l}70 \\
18 \\
12 \\
\end{array}$ & $\begin{array}{c}46 \\
15 \\
4 \\
\end{array}$ & $\begin{array}{c}70.8 \\
23.1 \\
6.2 \\
\end{array}$ & $\begin{array}{c}24 \\
3 \\
8 \\
\end{array}$ & $\begin{array}{c}68.6 \\
8.6 \\
22.9 \\
\end{array}$ & $7.567^{\mathrm{FE}}$ & $0.024 *$ \\
\hline $\begin{array}{l}\text { Income } \\
\text { Enough } \\
\text { Not enough } \\
\text { Enough and save from } \\
\text { it }\end{array}$ & $\begin{array}{l}42 \\
17 \\
41\end{array}$ & $\begin{array}{c}31 \\
3 \\
31\end{array}$ & $\begin{array}{c}47.7 \\
4.6 \\
47.7\end{array}$ & $\begin{array}{l}11 \\
14 \\
10\end{array}$ & $\begin{array}{l}31.4 \\
40.0 \\
28.6\end{array}$ & 20.217 & $0.000 * *$ \\
\hline $\begin{array}{l}\text { Educational level } \\
\text { Illiterate }\end{array}$ & 48 & 39 & 60.0 & 9 & 25.7 & $\begin{array}{l}29.618 \\
\text { FE }\end{array}$ & $0.000 * *$ \\
\hline $\begin{array}{l}\text { Read and write } \\
\text { Intermediate certificate } \\
\text { University education }\end{array}$ & $\begin{array}{l}23 \\
17 \\
12\end{array}$ & $\begin{array}{l}19 \\
3 \\
4\end{array}$ & $\begin{array}{c}29.2 \\
4.6 \\
6.2\end{array}$ & $\begin{array}{c}4 \\
14 \\
8\end{array}$ & $\begin{array}{l}11.4 \\
40.0 \\
22.9\end{array}$ & & \\
\hline
\end{tabular}

$\mathrm{X}^{2}$ Chi Square test

FE Expected cell count less than 5, Fisher's Exact test was used.

* Statistically significant at $\mathrm{p}<0.05$

** Highly statistically significant at $\mathrm{p}<0.01$

Table 4 demonstrates a highly statistically significant difference between awareness of a healthy lifestyle and age, place of residence, income, and educational level. Furthermore, among the elderly adults investigated, there was a statistically significant difference in awareness of a healthy lifestyle and occupation. 
Table 5 Relation between body mass index and older people's quality of life, independence in activities of daily living, severity of depression and awareness on healthy lifestyle among studied subjects.

\begin{tabular}{|c|c|c|c|c|c|c|c|}
\hline & \multirow[b]{2}{*}{ No } & \multicolumn{4}{|c|}{ Body Mass Index } & \multirow[b]{2}{*}{$\mathrm{X}^{2}$} & \multirow[b]{2}{*}{$P$ value } \\
\hline & & $\begin{array}{l}\text { Less } \\
\text { than } \\
18.5\end{array}$ & $\begin{array}{c}\text { From } \\
18.5 \text { to } \\
\text { less } \\
\text { than } \\
24.9\end{array}$ & $\begin{array}{l}\text { From } \\
25 \text { to } \\
\text { less } \\
\text { than } \\
29.9\end{array}$ & $\begin{array}{l}30 \text { or } \\
\text { more }\end{array}$ & & \\
\hline $\begin{array}{l}\text { Older People's } \\
\text { Quality of Life }\end{array}$ & & & & & & & \\
\hline Insufficient & 24 & 0 & 4 & 14 & 6 & $\underset{\mathrm{FE}}{26.884}$ & $0.000 * *$ \\
\hline Sufficient & 76 & 39 & 11 & 17 & 9 & & \\
\hline \multicolumn{8}{|l|}{$\begin{array}{l}\text { Independence in } \\
\text { Activities of Daily } \\
\text { Living }\end{array}$} \\
\hline Insufficient & 23 & 6 & 0 & 11 & 6 & $\underset{\mathrm{FE}}{11.365}$ & $0.007 * *$ \\
\hline Sufficient & 77 & 33 & 15 & 20 & 9 & & \\
\hline \multicolumn{8}{|l|}{$\begin{array}{l}\text { Severity of } \\
\text { Depression }\end{array}$} \\
\hline Normal & 11 & 8 & 3 & 0 & 0 & $\underset{\mathrm{FE}}{90.425}$ & $0.000 * *$ \\
\hline Mild & 13 & 3 & 0 & 7 & 3 & & \\
\hline Moderate & 25 & 3 & 0 & 13 & 9 & & \\
\hline Sever & 23 & 0 & 12 & 8 & 3 & & \\
\hline Very sever & 28 & 25 & 0 & 3 & 0 & & \\
\hline \multicolumn{8}{|l|}{$\begin{array}{l}\text { Awareness on } \\
\text { Healthy Lifestyle } \\
\text { during Aging }\end{array}$} \\
\hline Insufficient & 65 & 31 & 12 & 13 & 9 & 12.495 & $0.006^{* *}$ \\
\hline Sufficient & 35 & 8 & 3 & 18 & 6 & & \\
\hline
\end{tabular}

$\mathrm{X}^{2}$ Chi Square test

$\mathrm{FE}$ Expected cell count less than 5, Fisher's Exact test was used.

** Highly statistically significant at $\mathrm{p}<0.01$

Table 5 shows a highly statistically significant difference between body mass index and older people's quality of life, independence in activities of daily living, severity of depression, and awareness of healthy lifestyle choices during aging among studied elderly people. 
Table6: Relation between chronic diseases and older people's quality of life among studied subjects.

\begin{tabular}{|c|c|c|c|c|c|c|c|}
\hline & \multirow{3}{*}{ No } & \multicolumn{4}{|c|}{ Older People's Quality of Life } & \multirow{3}{*}{$\mathbf{X}^{2}$} & \multirow{3}{*}{ P value } \\
\hline & & \multicolumn{2}{|c|}{ Insufficient } & \multicolumn{2}{|c|}{ Sufficient } & & \\
\hline & & No. & $\%$ & No. & $\%$ & & \\
\hline $\begin{array}{l}\text { Hypertension } \\
\text { Yes } \\
\text { No }\end{array}$ & $\begin{array}{c}91 \\
9\end{array}$ & $\begin{array}{c}21 \\
3\end{array}$ & $\begin{array}{l}87.5 \\
12.5\end{array}$ & $\begin{array}{c}70 \\
6\end{array}$ & $\begin{array}{c}92.1 \\
7.9\end{array}$ & FE & 0.445 \\
\hline $\begin{array}{l}\text { Diabetes Mellitus } \\
\text { Yes } \\
\text { No }\end{array}$ & $\begin{array}{l}65 \\
35\end{array}$ & $\begin{array}{c}17 \\
7\end{array}$ & $\begin{array}{l}70.8 \\
29.2\end{array}$ & $\begin{array}{l}48 \\
28\end{array}$ & $\begin{array}{l}63.2 \\
36.8\end{array}$ & 0.472 & 0.492 \\
\hline $\begin{array}{l}\text { COPD } \\
\text { Yes } \\
\text { No }\end{array}$ & $\begin{array}{l}15 \\
85\end{array}$ & $\begin{array}{c}3 \\
21\end{array}$ & $\begin{array}{l}12.5 \\
87.5\end{array}$ & $\begin{array}{l}41 \\
35\end{array}$ & $\begin{array}{l}53.9 \\
46.1\end{array}$ & 12.717 & $0.000 * *$ \\
\hline
\end{tabular}

$\mathrm{X}^{2}$ Chi Square test

${ }^{\mathrm{FE}}$ Expected cell count less than 5, Fisher's Exact test was used.

** Highly statistically significant a

Table 6 demonstrates a highly statistically significant difference between older people's quality of life and chronic obstructive pulmonary diseases among studied elderly people. In addition, there was no significant relation between hypertension and diabetes with older people's quality of life.

Table (7): Relation between total quality of life, independence in activities of daily living, severity of depression and awareness on healthy lifestyle and risk factors among studied subjects.

\begin{tabular}{|c|c|c|c|c|c|c|}
\hline & \multicolumn{4}{|c|}{ Total quality of life } & \multirow{3}{*}{$\mathrm{t}$} & \multirow{3}{*}{$\mathrm{p}$} \\
\hline & \multicolumn{2}{|c|}{ Sufficient } & \multicolumn{2}{|c|}{ Insufficient } & & \\
\hline & $\begin{array}{c}\text { Mea } \\
\mathrm{n}\end{array}$ & SD & $\begin{array}{c}\text { Mea } \\
\mathrm{n}\end{array}$ & $\mathrm{SD}$ & & \\
\hline $\begin{array}{c}\text { Independence in activities } \\
\text { of daily living }\end{array}$ & 69.29 & $\begin{array}{c}11.9 \\
8\end{array}$ & $\begin{array}{c}58.4 \\
0\end{array}$ & $\begin{array}{c}11.0 \\
4\end{array}$ & 3.951 & $0.000 * *$ \\
\hline Severity of depression & 19.66 & 8.15 & $\begin{array}{c}17.0 \\
8\end{array}$ & 4.29 & 1.479 & 0.142 \\
\hline $\begin{array}{c}\text { Awareness on healthy } \\
\text { lifestyle }\end{array}$ & 47.42 & $\begin{array}{c}13.6 \\
3\end{array}$ & $\begin{array}{c}60.4 \\
1\end{array}$ & $\begin{array}{c}13.4 \\
2\end{array}$ & $\begin{array}{c}34.56 \\
5\end{array}$ & $0.000 * *$ \\
\hline
\end{tabular}

* Statistically significant at $\mathrm{p}<0.05$

** Highly statistically significant at $\mathrm{p}<0.01$

Table (7) demonstrates that there is a very statistically significant relationship between the tested sample's freedom in daily activities and their overall quality of life. 
Furthermore, there was a statistically significant relationship between the study sample's awareness of a healthy lifestyle and their overall quality of life.

\section{Discussion}

A health indicator is a metric that sums together data on a certain priority area in population health or health system performance. It aids health authorities and institutions in monitoring the health of their populations and tracking the effectiveness of their local health systems. Chronic diseases, as well as associated indicators, are a major global health problem at the moment. Chronic diseases are characterized by complicated causation, various risk factors, extensive incubation periods, a long course of illness, and functional impairment in general. In terms of cause and prevention of chronic diseases, indicators can have positive or negative consequences Petersen et al. ${ }^{(16)}$.

In terms of sociodemographic characteristics, this study revealed that more than half of the studied samples were males, more than one third were between 60 and 65 years old, and less than one third were between 70 and 75 years old. Furthermore, three-quarters of the studied sample reside in urban areas, while more than half of them are married, while less than half are widowers. Less than three-quarters of the studied samples were retired and less than half of them had enough monthly income. In addition, nearly half of them were illiterate.

Regarding the medical history of chronic diseases, the present study result clarifies that the majority of the studied sample has hypertension, followed by diabetes mellitus. This result is in line with Badr and Shaheen (17), who studied the health status, family support, and depression among elderly people with chronic diseases in Benha City and found that hypertension and diabetes were the most prevalent diseases among elderly people. Also, this result agreed with Shao and Dai, (18), who found that hypertension was the most prevalent disease in his study. This finding may be due to physiological aging changes, bad lifestyle, and genetic factors for elderly patients.

Regarding quality of life assessment, this result demonstrated that life overall, 
religion and culture domains were found to have the highest mean score of QOL. This result is in line with Rodgers et al., (19), who studied the effect of functional ability on quality of life among diabetic elderly in Basion city and mentioned that life overall and cultural domains had the highest main score. This could be attributed primarily to the practice of Egyptian culture and religion as Muslims and Christians, where there is a close relationship between religion and parent-child relationships.In Egyptian culture, children should look after their parents and respect older people, which are considered meritorious deeds.

In accordance to, Independence control over life and financial circumstances domains the mean score were the lowest in present study. This finding is consistent with that of Moradi et al. ${ }^{(20)}$, who investigated the quality of life (QOL) and its factors among elderly people in Sri Lanka's rural community. Financial conditions and autonomous control over life domains got the lowest mean scores, according to the study. This discovery is related to elderly people's comorbidity and the ageing process.

In relation to the awareness of the elderly regarding healthy lifestyles and risk factors, the current study illustrated that there was poor knowledge of the studied sample regarding eating habits, physical activities, sleeping hours, and regular doctor follow-up. This resulted In agreement with Gomaa et al. ${ }^{(21)}$ who studied the lifestyle among the elderly with Chronic Obstructive Pulmonary Disease (COPD) and found that the patients' knowledge was not good about the pre-mentioned aspects. This result disagreed with Tyagi and Mishra ${ }^{(22)}$ who studied the awareness of the elderly with chronic disease about healthy lifestyles, and the study showed good knowledge about physical exercise, sleeping, and eating habits. In my opinion, this result might be due to the nature of life and to lower educational and cultural levels.

In terms of smoking among the elderly, this study demonstrated that around twothirds of the elderly were nonsmokers. This finding is consistent with that of Elbaz et al. (23) who investigated smoking as a risk factor for hypertension and discovered that only one-third of the elderly were smokers, while the other two-thirds were nonsmokers. Furthermore, Abdel-Hady and El-Gilany ${ }^{(24)}$ found that, despite the reduced frequency of smoking among elderly people, older smokers face increased 
hazards from smoking because they have smoked longer, are heavier smokers, and are more likely to develop smoking-related illnesses. This could be due to the increased risks of cardiovascular disease, hypertension, diabetes, and respiratory diseases among the elderly who smoke. This decline is the result of an increased prevalence of quitting and differential mortality among smokers and nonsmokers.

As regard to body mass index (BMI), this result demonstrated that the majority of the studied sample had a normal BMI of between 23 and 25.9. This result is consistent with the study conducted by Awad et al. ${ }^{(25)}$ who studied health literacy, health risk behavior, and lifestyle issues in elderly people with chronic diseases and found that about two-thirds of the studied sample had normal BMI. Moreover, this result disagreed with the study done by Saquib et al. ${ }^{(26)}$ on the prevalence of chronic diseases among Saudi men, and the results revealed that only one third of the elderly had a normal body mass index. Although these study results show a normal body mass index for elderly patients, they are unhealthy. This finding might be due to the fact that BMI is only one indicator of health to assess for weight and height, but it does not account for body composition, so you can be in the normal category and be very unhealthy or in the overweight category and be very healthy.

Regarding the health system indicators in terms of accessibility of health care offered to the studied sample, the results showed that the majority of the elderly have difficulty accessing health care. This result agreed with Almeida et al., (27), who studied access to care among elderly Indians with chronic diseases and found that half of the elderly experienced difficulties accessing health care in general. This could be due to chronic diseases that increase the incidence of disability and, in turn, access to health care. In developing countries like Egypt, poor people, lack of transportation, specialized clinics, and the absence of care givers are all associated with the inability to access health care.

In terms of total severity of depression, this result indicated that more than one quarter of the studied sample were suffering from very severe depression, less than one quarter were suffering from severe depression, one quarter had moderate depression, and more than one tenth had mild depression, and about a tenth of them 
were normal. This contradicts the findings of Mohamed et al. ${ }^{(28)}$, who investigated the prevalence of depression in elderly people with diabetes and discovered that more than half of the people studied were normal, more than a tenth of the cases had very severe depression, and less than $1 \%$ had severe depression. It could be attributed to the increased prevalence of chronic diseases linked to ageing. Depression is linked to a variety of chronic diseases, financial hardship, stressful life events, self-perception, and low self-esteem, all of which are linked to a person's reliance on others.

Concerning the relationship between socio-demographic characteristics and quality of life, this result showed a highly statistically significant difference between age, residence, and educational level and QoL. This result is in agreement with Christiane et al. ( ${ }^{\text {29) }}$, who studied the relationship between sociodemographic characteristics and QoL in a study of elderly people in Brazil and found that the level of education confers several advantages for health, such as influences on psychosocial factors and behavior. This might be due to individuals with a higher educational level being less likely to be exposed to risk factors for diseases. In addition, higher education promotes access to information and the modification of lifestyle to adopt healthy habits.

In accordance to relation between chronic diseases and older people quality of life this study result demonstrated that there was a highly statistically significant difference between chronic obstructive pulmonary diseases and quality of life this result is in line with Persson et al. (30) Who mentioned that there is strong bond between COPD and elderly quality of life this is could be related to emotional stress and sleep disturbances.

In terms of the correlation between socio-demographic characteristics and awareness of a healthy lifestyle, this study finding demonstrated that there was a highly statistically significant difference between residence, age, and educational level with awareness of a healthy lifestyle. This finding contradicted the findings of Shafiee et al. (31), who found no significant relationship between age, residence, and educational level and awareness of a healthy lifestyle. In my opinion, a high level of education helps people practice healthy lifestyle behaviors. A well ventilated 
environment and resident area help them to be healthy.

Regarding the correlation between body mass index and performing activities of daily living, this study result revealed a highly statistically significant difference between body mass index and independence in activities of daily living, in agreement with Borda et al. ${ }^{(32)}$ who found a significant association between underweight and obesity in performing basic activities of daily living. This result might be related to the majority of my patients having a normal body mass index, and in turn, they were doing better in ADL. The elderly with a normal body mass index have good muscle mass to perform ADL.

\section{Conclusion}

In light of the study findings, it was concluded that more than half of the chronic disease patients were men, and the majority of them lived in urban regions. Threequarters of the elderly reported a good quality of life, whereas one-quarter had a poor quality of life. In addition, there was a highly statistically significant difference between older people's quality of life and chronic obstructive pulmonary diseases among studied elderly people. In addition, there was no significant relation between hypertension and diabetes with older people's quality of life. More than three-quarters of the participants in the study were independent, and less than a third required assistance with activities of daily living, including bathing, toileting, and transferring. Almost the majority of the studied sample had depression of varying severity as a result of chronic diseases. More than half suffered from severe depression, one quarter had moderate depression, and more than a tenth had mild depression. More than three-quarters of the elderly were nonsmokers. Almost the majority of the studied samples had a normal body mass index, while less than one third were overweight or obese. Approximately two-thirds of the studied sample lacked adequate awareness of healthy lifestyle and risk factors for chronic diseases, particularly in terms of healthy diet and physical activity. Almost all the studied samples face problems accessing healthcare services, and more than half need to travel to another location to get the service they need. 


\section{Recommendations}

\section{Based on the study findings, it is recommended that:}

1- $\quad$ Replication of the study using a large study sample in different settings to generalize the results.

2- Develop an educational program to enhance the awareness of nurses on chronic diseases, it is indicators, and significance of monitoring process for improvement of elderly health

3- Develop new electronic system for documentation in the hospital and include the health indicators of chronic diseases in the monitoring process on regular and routine basis

4- Establish specialized geriatric clinics designed well for responding to elderly needs and helping them to manage chronic diseases.

\section{Declaration of Conflicts of interest:}

The authors whose names are listed above have NO affiliations with or involvement in any organization or entity with any financial interest or non-financial interest (such as personal or professional relationships, affiliations, knowledge or beliefs) in the subject matter or materials discussed in this manuscript.

\section{Source of Funding:}

self-Funding

\section{References}

1- $\quad$ Saeed, K., Menzo, E. L., Szomstein, S., \& Rosenthal, R. J. (2021). Elderly High Risk Patients Undergoing Laparoscopic Sleeve Gastrectomy. In Laparoscopic Sleeve Gastrectomy (pp. 347-363). Springer, Cham.

2- $\quad$ Amarya, S., Singh, K., \& Sabharwal, M. (2018). Ageing process and physiological changes. In Gerontology. IntechOpen.

3- Dodig, S., Čepelak, I., \& Pavić, I. (2019). Hallmarks of senescence and aging. Biochemia medica: Biochemia medica, 29(3), 483-497.

4- Bernell, S. \& Howard, S.(2016): Use your words carefully: what is a chronic disease?. Frontiers in public health, America 4,159.Available on line on 
https://www.ncbi.nlm.nih.gov/pmc/articles/PMC4969287/

5- Chiaranai, C., Chularee, S., \& Srithongluang, S. (2018). Elderly living with chronic diseases. Geriatric Nursing, 39(5), 513-520

6- World health organization. (2020). Noncommunicable Diseases Global Monitoring Framework: Indicator Definitions and Specifications $1 \mid P$ a $G$ E NCD Global Monitoring Framework: Indicator Definitions and Specifications Table of Contents Introduction Global Monitoring Framework Global Targets for NCDs Setting National Targets Reporting on the Global NCD Indicators [accessed 6 December 2021] 7- $\quad$ Griffin, C. D. (2017). A Primary Care Nursing Perspective on Chronic Disease Prevention and Management. Delaware Journal of Public Health, 3(1), 78.

8- Romero-Sandoval, N., Canelos, S. R., Sánchez-Pérez, H. J., Romero, R., Cornejo, F., \& Martín-Mateo, M. (2020). Non-Communicable Chronic diseases and Structural Indicators in an Epidemiological Transition Country. Open Journal of Epidemiology, 10(1), 32-42.

9- World health organization. (2020). Noncommunicable Diseases Global Monitoring Framework: Indicator Definitions and Specifications $1 \mid P$ a G E NCD Global Monitoring Framework: Indicator Definitions and Specifications Table of Contents Introduction Global Monitoring Framework Global Targets for NCDs Setting National Targets Reporting on the Global NCD Indicators [accessed 6 December 2021] 10- Ahmed, M., Mohammed, S. A., \& Abd-Elaziz, N. M. (2020). Prevalence of Disabilities among Elderly in rural area at Assiut district, Egypt. Assiut Scientific Nursing Journal, 8(22), 187-196.

11- Moradi, M., Daneshi, F., Behzadmehr, R., Rafiemanesh, H., Bouya, S., \& Raeisi, M. (2020). Quality of life of chronic heart failure patients: a systematic review and metaanalysis. Heart failure reviews, 25(6), 993-1006.

12- Bonilla-Sierra, P., Vargas-Martínez, A. M., Davalos-Batallas, V., Leon-Larios, F., \& Lomas-Campos, M. D. L. M. (2020). Chronic diseases and associated factors among older adults in Loja, Ecuador. International Journal of Environmental Research and Public Health, 17(11), 4009.

13- Buyl, R., Beogo, I., Fobelets, M., Deletroz, C., Van Landuyt, P., Dequanter, S., ... \& Gagnon, M. P. (2020). e-Health interventions for healthy aging: a systematic review. Systematic reviews, 9, 1-15. 
14- Braithwaite, J., Hibbert, P., Blakely, B., Plumb, J., Hannaford, N., Long, J. C., \& Marks, D. (2017). Health system frameworks and performance indicators in eight countries: a comparative international analysis. SAGE open medicine, 5, 2050312116686516.

15- Nixon, N., Guo, B., Garland, A., Kaylor-Hughes, C., Nixon, E., \& Morriss, R. (2020). The bi-factor structure of the 17-item Hamilton Depression Rating Scale in persistent major depression; dimensional measurement of outcome. PloS one, 15(10), e0241370.

16- Petersen, I., Welch, C. A., Nazareth, I., Walters, K., Marston, L., Morris, R. W., \& Pham, T. M. (2019). Health indicator recording in UK primary care electronic health records: key implications for handling missing data. Clinical epidemiology, 11, 157.

17- Badr, S., \& Shaheen, H. (2017). Health status, family support and depression among residents of elderly homes and those living with Families in Benha City and Associated Factors. Egyptian Journal of Community Medicine, 35(1).

18- Shao, W., Fu, J., \& Dai, Y. (2021, July). Design of Medicine Box for the Elderly with Chronic Diseases. In International Conference on Applied Human Factors and Ergonomics (pp. 443-449). Springer, Cham.

“GoogleScholar,” Scholar.google.com <https://scholar.google.com/scholar?as_ylo=201 $7 \& q=$ Shao $>$ [accessed 6 December 2021]

19- Rodgers, V., Neville, S., \& La Grow, S. (2017). Health, functional ability and life satisfaction among older people 65 years and over: a cross-sectional study. Contemporary nurse, 53(3), 284-292.

20- Moradi, M., Daneshi, F., Behzadmehr, R., Rafiemanesh, H., Bouya, S., \& Raeisi, M. (2020). Quality of life of chronic heart failure patients: a systematic review and meta-analysis. Heart failure reviews, 25(6), 993-1006.

21- Gomaa, W. S., Mohamed, H. A., \& Morad, A. H. (2020). Assessment Lifestyle for Patients with Chronic Obstructive Pulmonary Disease. Egyptian Journal of Health Care, 11(2), 273-285.

22- Tyagi, Neeraj, and Sunita Mishra. (2020). "A STUDY on AWARENESS for LATE ADULT on HEALTHY LIFESTYLE towards NUTRIGENOMIC KNOWLEDGE," Plant Archives, 20.2: 3737-41 [accessed 6 December 2021] 
23- Elbaz, W. F., Eissa, S. S., Mohamed, R. A., Aly, N. K., \& Reda, T. M. (2018). Essential Hypertension among Egyptian Adults. The Egyptian Journal of Hospital Medicine, 61(1), 643-652.

24- Abdel-Hady, D., \& El-Gilany, A. H. (2020). Tobacco use and its associated factors among older people: a community-based study in Egypt. 8 million people diefrom tobacco.

25- Awad, S. A., Fahmy, H. D., Hassanen, R. H., \& Abd-ELaziz, S. A. E. H. (2018). Assessment of Health Literacy and Health Risk Behaviors among Elderly at Assiut City Egypt. Assiut Scientific Nursing Journal, 6(15), 1-7.

26- Saquib, N., Saquib, J., Alhadlag, A., Albakour, M. A., Aljumah, B., Sughayyir, M., ... \& Al-Mazrou, A. (2017). Chronic disease prevalence among elderly Saudi men. International journal of health sciences, 11(5), 11.

27- Almeida, A. P. S. C., Nunes, B. P., Duro, S. M. S., \& Facchini, L. A. (2017). Socioeconomic determinants of access to health services among older adults: a systematic review. Revista de saude publica, 51, 50.

28- Mohamed, M. M., Fawzy, M., Selim, F., \& Sakr, M. (2020). Depression and Its Relation to Diabetes Control and Complications in Type 2 Diabetic Patients in Police Authority Hospital. The Egyptian Journal of Hospital Medicine, 81(3), 1538-1545.

29- Christiane C, Paulo M, Alves AT (2017). Educational level, socioeconomic status and relationship with quality of life in elderly residents of the city of Porto Alegre/RS, Brazil. Brazilian Journal of Pharmaceutical Sciences. ;46(4):805-10

30- Persson, H. L., Lyth, J., \& Lind, L. (2020). The health diary telemonitoring and hospital-based home care improve quality of life among elderly multimorbid COPD and chronic heart failure subjects. International journal of chronic obstructive pulmonary disease, 15, 527.

31- Shafiee, M., Hazrati, M., Motalebi, S. A., Gholamzade, S., Ghaem, H., \& Ashari, A. (2020). Can healthy life style predict successful aging among Iranian older adults?. Medical Journal of the Islamic Republic of Iran, 34, 139.

32- Borda, M., Venegas, L., Garcia-Cifuentes, E., Gomez, R., Cano-Gutierrez, C., Tovar-Rios, D., ... \& Soennesyn, H. (2020). Body Mass Index, Performance of Activities of Daily Living and Cognition: Analysis in Colombian and Korean Older Adults. 